\title{
Intravenous Single-Dose Toxicity of Redaporfin-Based Photodynamic Therapy in Rodents
}

\author{
Luis B. Rocha ${ }^{1,2}$, Fábio Schaberle ${ }^{1}$, Janusz M. Dąbrowski ${ }^{3}$, Sérgio Simões ${ }^{2}$ \\ and Luis G. Arnaut ${ }^{4, *}$ \\ Received: 16 November 2015; Accepted: 2 December 2015; Published: 8 December 2015 \\ Academic Editors: Michael R. Hamblin and Ying-ying Huang \\ 1 Luzitin SA, S. Martinho do Bispo, Coimbra 3045-016, Portugal; lrocha@luzitin.pt (L.B.R.); \\ fschaberle@luzitin.pt (F.S.) \\ 2 Bluepharma-Indústria Farmacêutica SA, S. Martinho do Bispo, Coimbra 3045-016, Portugal; \\ ssimoes@bluepharma.pt \\ 3 Faculty of Chemistry, Jagiellonian University, Krakow 30-060, Poland; jdabrows@chemia.uj.edu.pl \\ 4 Chemistry Department, University of Coimbra, Coimbra 3004-535, Portugal \\ * Correspondence: lgarnaut@ci.uc.pt; Tel.: +351-239-854-484; Fax: +351-239-827-703
}

\begin{abstract}
We assessed the tolerability and safety in rodents of a single intravenous (i.v.) dose of redaporfin, a novel photosensitizer for Photodynamic Therapy (PDT) of cancer. Two approaches were used to evaluate acute toxicity: (i) a dose escalation study in BALB/c mice to evaluate the maximum tolerated dose of redaporfin; and (ii) a safety toxicology study in Wistar rats, of a single dose of redaporfin, with or without illumination, to evaluate possible signs of systemic toxicity. Redaporfin formulation was well tolerated by mice, with no signs of adverse reactions up to $75 \mathrm{mg} / \mathrm{kg}$. In rats, there were no relevant changes, except for a significant, but transient, increase in the blood serum markers for hepatic function and muscle integrity, and also on neutrophil counts, observed after the application of light. The overall results showed that redaporfin-PDT is very well tolerated. No abnormalities were observed, including reactions at the injection site or skin phototoxicity, although the animals were maintained in normal indoor lighting. Redaporfin also showed a high efficacy in the treatment of male BALB/c mice with subcutaneously implanted colon (CT26) tumours. Vascular-PDT with $1.5 \mathrm{mg} / \mathrm{kg}$ redaporfin and a light dose of $74 \mathrm{~J} / \mathrm{cm}^{2}$ led to the complete tumour regression in $83 \%$ of the mice.
\end{abstract}

Keywords: photodynamic therapy; cancer treatment; bacteriochlorin; redaporfin; intravenous formulation; single-dose toxicity; rodents

\section{Introduction}

Photodynamic Therapy (PDT) is generally recognized as a safe and effective strategy and is approved to treat several forms of cancer. PDT requires the simultaneous combination of a drug, molecular oxygen, and light of a specific wavelength to generate reactive oxygen species (ROS), which are responsible for the destruction of tumour cells [1,2]. The antitumour effect of PDT is related to three distinct effects responsible for tumour cell death: oxidative damage promoted by ROS leading to apoptosis, autophagy or necrosis; shutdown of the tumour blood vessels that interrupts oxygen and nutrient supply; and eventually an antitumor immune response induced by PDT [3,4]. A most often presented advantage of PDT over other cancer therapies is the use of drugs-called photosensitizers (PS) - that are inactive in the absence of light. It is expected that the PS used in PDT are not toxic, or immunogenic, before they are activated by light of a wavelength specifically absorbed by the PS. When the PS is administered with an injectable solvent, the concerns on the toxicity extend to the drug formulation. The toxicity of PS and drug formulation must be assessed before entering clinical trials. 
Porfimer sodium (Photofrin ${ }^{\circledR}$ ) is currently the most used photosensitizer for systemic administration. It is clinically employed for the treatment of lung, oesophagus, bile duct, bladder, brain and ovarian tumours. Temoporfin (Foscan ${ }^{\circledR}$ ) is a photosensitizer clinically applied in Europe for the treatment of head \& neck, lung, brain, skin and bile duct cancer. Verteporfin (Visudyne ${ }^{\circledR}$ ) met with considerable success as a photosensitizer in the treatment of age-related macular degeneration (AMD), and is also applied in PDT of prostate and pancreatic cancers. Every new drug candidate must be subjected to extensive nonclinical toxicology programs to demonstrate that it has acceptable profiles of tolerability and safety, and guarantee the lowest possible level of risk for the participants in the first-in-human trial. The general requirements for these toxicology studies are described in the harmonized guideline ICH M3(R2), from the International Council for Harmonisation of Technical Requirements for Pharmaceuticals for Human Use, and are further detailed in the comprehensive set of guidelines related to safety (S guidelines) [5]. PS for PDT may elicit intrinsic adverse reactions, may employ drug formulations with some toxicity, or may show toxicity as a consequence of the illumination protocol. This last concern is specific of PDT and requires the design of safety evaluation strategies that take into consideration the combination of drug and light [6,7].

We have been involved in the development of a fluorinated sulphonamide bacteriochlorin named redaporfin-5,10,15,20-tetrakis (2,6-difluoro-3- $N$-methylsulfamoylphenyl) bacteriochlorin, code name LUZ11 - for PDT of cancer. Redaporfin presents near-ideal properties [8] and proved to be highly effective in the treatment of mice with subcutaneous colon CT26 tumour, with significant antitumor effects on distant metastasis, attributed to its ability to activate the host immune system $[9,10]$. Redaporfin is amphiphilic with an $n$-octanol: water partition coefficient of 80 $\left(\log P_{\mathrm{OW}}=1.9\right)$ [8]. Redaporfin is not soluble in water and tends to aggregate when a stock solution of redaporfin in an organic solvent (e.g., ethanol or dimethylsulfoxide) is added to water. In order to avoid aggregation, the redaporfin formulation contains a small amount of Cremophor EL ${ }^{\circledR}$ (CrEL). CrEL has been extensively used and characterized to deliver drugs with $\log P_{\mathrm{OW}}>1$. CrEL forms micelles in aqueous solutions and its critical micellar concentration is $0.009 \%$ (weight/volume) in protein-free aqueous solution [11]. It was noted that CrEL concentrations $>0.03 \%$ in human serum lead to lipoprotein degradation [12]. Hypersensitivity reactions of drugs formulated with CrEL have been associated with concentrations $>0.2 \%$ in plasma of cancer patients [13], but the adverse effects can be countered by pre-medication. Considering that the human blood plasma volume is $35 \mathrm{~mL} / \mathrm{kg}$, a total safe dose of CrEL should be $<0.07 \mathrm{~mL} / \mathrm{kg}$. However, the low solubility of very lipophilic drugs may require an increase in the CrEL content in the drug formulation, which then requires pre-medication to control adverse effects. For example, the paclitaxel formulation is associated with the administration of $0.37 \mathrm{~mL} / \mathrm{kg}$ of CrEL [14], but hypersensitivity reactions can be avoided with, for example, pre-medication with dexamethasone [15]. The minimum value of CrEL may alternatively be limited by its critical micellar concentration (CMC $>0.003 \mathrm{~mL} / \mathrm{kg})$. As will be shown below, our toxicology study employed a redaporfin formulation in $\mathrm{CrEL} / \mathrm{EtOH} / \mathrm{NaCl}$ 0.9\% (1.2:5.7:93.1, v:v:v) with a redaporfin concentration of $0.86 \mathrm{mg} / \mathrm{mL}$ to administer a redaporfin dose of $1.5 \mathrm{mg} / \mathrm{kg}$, i.e., a CrEL dose of $0.021 \mathrm{~mL} / \mathrm{kg}$. This is above the CMC and well within the limits of the safe dose level. On the other hand, the dose escalation study explored redaporfin doses up to $75 \mathrm{mg} / \mathrm{kg}$ and the CrEL content of the formulation used in this study had to be increased to the proportion CrEL/EtOH/NaCl 0.9\% (5:10:85, v:v:v), leading to the a total CrEL dose of $0.5 \mathrm{~mL} / \mathrm{kg}$.

European Medicines Agency (EMA) recently granted the status of orphan drug designation for redaporfin-PDT of biliary track cancer [16], and redaporfin entered clinical trials with patients with advanced head and neck cancer [17]. This work reports preliminary safety studies designed to assess the safety and tolerability of redaporfin-PDT in the clinical trial application of redaporfin. The studies cover a dose escalation study in mice to evaluate the Maximum Tolerated Dose (MTD) of redaporfin in its formulation but without illumination, and a systemic toxicity study in rats, with and without illumination. Since the goal is for the redaporfin-PDT in the clinic to be effective with only one treatment, both studies focused on the acute reactions elicited by a single session of PDT. This work 
also presents an efficacy study designed to test a $1.5 \mathrm{mg} / \mathrm{kg}$ dose of redaporfin with a light dose of $74 \mathrm{~J} / \mathrm{cm}^{2}$ in vascular-PDT, with a drug-light interval (DLI) of $15 \mathrm{~min}$. These doses are higher than those used in previous studies with redaporfin $[9,10]$, and motivated the use of male, rather than female, BALB/c mice in this study, to take advantage of their larger size ( $25 \mathrm{~g}$ vs. $20 \mathrm{~g}$ ). The use of higher doses in this study explores the relation between the onset of adverse effects and the size of the animal-models.

\section{Results}

\subsection{Dose Escalation Study}

This study consisted in the i.v. administration of increasing concentrations of redaporfin formulation to female BALB/c mice, without illumination.

Throughout the study, there were no noticeable changes in the overall condition of the mice. No significant variations were observed in the average body weights (BW) in any of the study groups, including the control group that received the vehicle alone. The BW evolution over time after the administration of redaporfin for each group is presented in Table 1. The eyes, tail and paws of the animals were observed regularly and did not indicate signs of photosensitivity reactions due to exposure to indoor lighting. In addition, mice behaviour was consistent throughout the study, without signs of light avoidance during the handling procedures. Moreover, there were no signs of local reaction at the site of injection.

Mice from group G6 $(75 \mathrm{mg} / \mathrm{kg})$ started the study eight weeks after the other groups, once it was concluded that the injected redaporfin formulations up to $37.5 \mathrm{mg} / \mathrm{kg}$ did not cause any observable reaction in mice. This time gap accounts for the higher average body weight observed in G6 group as compared to the other groups.

\subsection{Safety Toxicology Study}

In this study, female Wistar rats received an i.v. injection of redaporfin formulation, followed or not, by laser illumination to evaluate possible signs of systemic toxicity, through standard clinical blood analysis.

All animals enrolled in this study survived until the time-points defined for terminal blood collection, without any observable signs of adverse reactions that could be associated with the i.v. administration of the redaporfin formulation, the vehicle alone or the PDT protocol. Changes in the general condition or normal behaviour of the animals were not detected, even in the group that received $15 \mathrm{mg} / \mathrm{kg}$ or in the irradiated groups. There was no sign of skin phototoxicity reactions when they were exposed to the standard laboratory illumination, which indicates the absence of light sensitivity under those conditions.

Three study groups were irradiated in the right thigh with a DLI of $15 \mathrm{~min}$, meaning that the rats were irradiated $15 \mathrm{~min}$ after the administration of redaporfin. On the following day, $24 \mathrm{~h}$ after illumination, the animals presented a significant inflammatory response in the irradiated leg, indicated by a large oedema, although it did not interfere with their movements. In addition, a necrotic eschar covering the irradiated area was visible $72 \mathrm{~h}$ after PDT in all animals from the irradiated groups. Possible signs of systemic toxicity were accessed by a standard set of clinical blood tests at selected time-points, post-administration/illumination. Such tests are routinely performed to evaluate acute and chronic toxicity reactions through the measurement of haematological parameters and biochemistry markers, and are very useful in the non-clinical evaluation of the safety profile of new drug candidates, including PS $[18,19]$. Generally, they provide relevant information about the circulatory homeostasis, liver and renal function or muscle injury [20]. 
Table 1. Mice body weight (g) over time after the i.v. injection of redaporfin formulation for each study group (average \pm SD).

\begin{tabular}{|c|c|c|c|c|c|c|c|c|c|c|c|}
\hline \multirow{2}{*}{ Group } & \multirow{2}{*}{$\begin{array}{c}\text { Redaporfin } \\
(\mathrm{mg} / \mathrm{kg})\end{array}$} & \multicolumn{10}{|c|}{ Days After Administration } \\
\hline & & $\mathbf{0}$ & 4 & 7 & 11 & 14 & 16 & 21 & 28 & 35 & 46 \\
\hline G0 & 0 & $21.9 \pm 0.6$ & - & $21.9 \pm 0.8$ & - & - & $22.2 \pm 1.0$ & - & $22.1 \pm 1.2$ & $22.4 \pm 0.8$ & - \\
\hline G1 & 15 & $22.0 \pm 0.7$ & - & $21.8 \pm 0.6$ & - & - & $22.4 \pm 0.6$ & - & $22.9 \pm 0.5$ & $23.1 \pm 0.6$ & - \\
\hline G2 & 21 & $22.0 \pm 1.0$ & - & $21.7 \pm 0.8$ & - & - & $22.1 \pm 0.9$ & - & $22.3 \pm 1.0$ & $22.1 \pm 1.1$ & - \\
\hline G3 & 26.3 & $21.4 \pm 0.5$ & - & $20.8 \pm 0.7$ & - & - & $21.0 \pm 0.7$ & - & $21.9 \pm 1.1$ & $21.7 \pm 0.4$ & - \\
\hline G4 & 30 & $22.8 \pm 0.9$ & - & $22.5 \pm 0.9$ & - & - & $22.6 \pm 1.0$ & - & $22.3 \pm 0.9$ & $23.4 \pm 1.0$ & - \\
\hline G5 & 37.5 & $21.9 \pm 1.2$ & - & $21.5 \pm 1.0$ & - & - & $21.7 \pm 1.0$ & - & $21.8 \pm 1.3$ & $22.2 \pm 1.0$ & - \\
\hline G6 & 75 & $24.4 \pm 1.7$ & $23.9 \pm 1.6$ & $24.2 \pm 1.7$ & $24.2 \pm 1.6$ & $24.2 \pm 1.6$ & - & $24.5 \pm 1.8$ & $25.5 \pm 1.6$ & - & $25.3 \pm 1.7$ \\
\hline
\end{tabular}


The detailed results of the blood tests performed for all study groups are presented in Appendix A (Table A1—haematology and Table A2—serum biochemistry). The values determined for the non-treated control group were found to be in the normal ranges for female Wistar rats with similar age, according to the supplier technical documents [21]. The haematology and serum biochemistry results obtained in the three non-irradiated groups, which received the vehicle alone, redaporfin at 1.5 or $15 \mathrm{mg} / \mathrm{kg}$, showed no significant differences in comparison to the non-treated control group. This demonstrates that a single i.v. administration of the redaporfin formulation, even at a dose of $15 \mathrm{mg} / \mathrm{kg}$, does not have a significant impact on the clinical blood parameters, thus showing no signs of systemic toxicity.

The comparison of the serum biochemistry results between the irradiated groups and the control group revealed significant differences on the markers for liver function and muscle damage. The results show that $24 \mathrm{~h}$ after PDT, there was a significant increase in the levels of the hepatic transaminases, aspartate aminotransferase (AST) and alanine aminotransferase (ALT), while alkaline phosphatase (ALP) remained unchanged (Figure 1). Together with the significant rise of lactate dehydrogenase (LDH) and creatine kinase (CK), which are normally associated with muscle damage [22], these results were probably a consequence of the destruction of skeletal muscle on the irradiated thigh caused by the photodynamic effect of the redaporfin-PDT. Nevertheless, $72 \mathrm{~h}$ after PDT the levels of all four markers had already decreased, and only AST and ALT remained significantly higher than in the control group. One week after PDT, all the altered biochemistry parameters have returned to their pre-PDT levels, indicating that the changes in liver function were transitory and probably a consequence of muscle damage, associated with the observed local tissue destruction caused by the PDT protocol. On the other hand, there were no significant alterations on the levels of renal function, such as urea, blood urea nitrogen, creatinine or total protein, which is a good indication that the kidneys were not affected by redaporfin and its formulation, nor by the photodynamic reaction elicited by the PDT protocol. It is important to note that, in the PDT treatment of an animal with a solid tumour, the destruction of skeletal muscle would by greatly reduced, since the illumination would be directed to the tumour mass and not to the muscle, which would probably reduce the alterations in the liver function found in this study. Nevertheless, in clinical studies of redaporfin-PDT should survey markers of liver function.

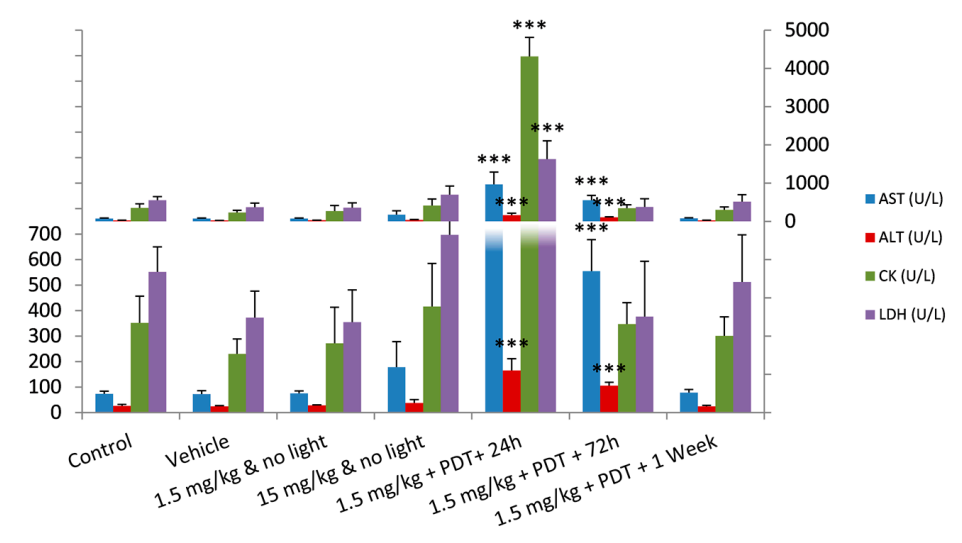

Figure 1. Summary of the most relevant results from serum biochemistry of Wistar rats, presented as average \pm SD. ( ${ }^{* * *}$ difference relative to the control group $-p<0.001$ ). The two panels present the same results in different scales to highlight the inter-group differences.

The haematology parameters of all test groups were largely unaffected in comparison to the control group, with only two statistically significant exceptions: a dramatic increase in the number of circulating neutrophils observed $24 \mathrm{~h}$ after PDT, and a decrease in the haemoglobin level $72 \mathrm{~h}$ after PDT. In addition, $24 \mathrm{~h}$ after PDT there was a significant decrease in the lymphocyte population relative to $1.5 \mathrm{mg} / \mathrm{kg}$ group but not significant in relation to the control group (Figure 2). The increase 
of the neutrophil population in circulation can be associated with the innate immune system response to a local insult, which triggers an acute inflammatory response [4,23]. This response was clearly observed in the form of a large oedema that extended through the whole leg of the animals, on the days that followed the illumination. On the third day after illumination, the population of circulating neutrophils was already decreasing, which can be an indication of their passage from the circulation into the damaged tissues [24]. One week after PDT, the number of neutrophils in the blood had already returned to the levels pre-PDT.

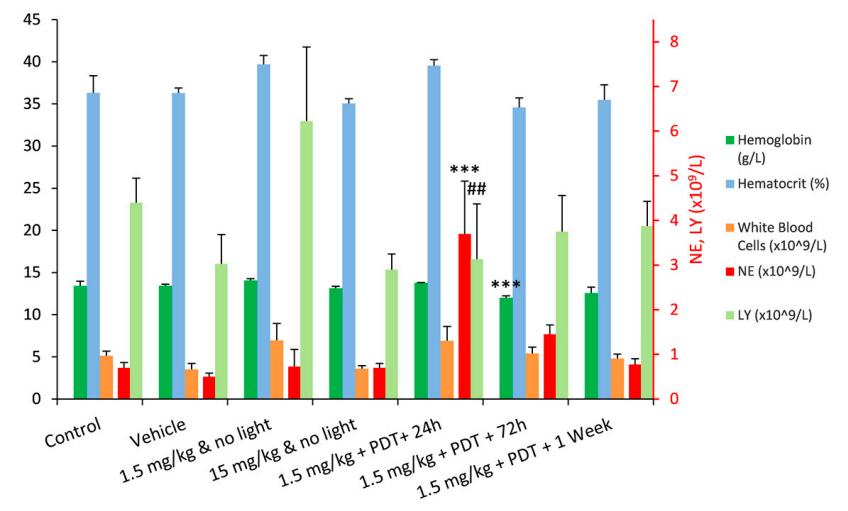

Figure 2. Summary of the most relevant results from Wistar rats haematology, presented as average \pm SD. The values for the neutrophils (NE) and lymphocytes (LY) populations are presented in the secondary vertical axis. (*** difference relative to the control group $-p<0.001$; \#\# difference relative to the $1.5 \mathrm{mg} / \mathrm{kg}$ group $-p<0.01)$.

\subsection{Photodynamic Efficacy of Redaporfin-PDT}

Figure 3 shows a Kaplan-Meier plot of the percentage of animals with local tumour control after one single treatment with $1.5 \mathrm{mg} / \mathrm{kg}$ redaporfin. The illumination was carried out for $9.5 \mathrm{~min}$ while redaporfin was confined in the vasculature (DLI $=15 \mathrm{~min}$ ) using $130 \mathrm{~mW}$ laser at $749 \mathrm{~nm}$. Interestingly, whereas a similar drug and light dose and the same DLI lead to overdosing in female BALB/c mice weighing approximately $20 \mathrm{~g}$ [10], with 3 months old male BALB/c mice weighing around $25 \mathrm{~g}$ this protocol did not lead to any PDT-induced lethality. Moreover, this protocol achieved a cure rate of $83 \%$. This remarkable long-term tumour response is due to extensive necrosis of all the illuminated area. The high photodynamic activity towards CT26 tumours may be explained by efficient generation of both singlet oxygen and hydroxyl radicals by redaporfin $[8,25]$, and the strong immune response triggered by the high local inflammation after PDT [10].

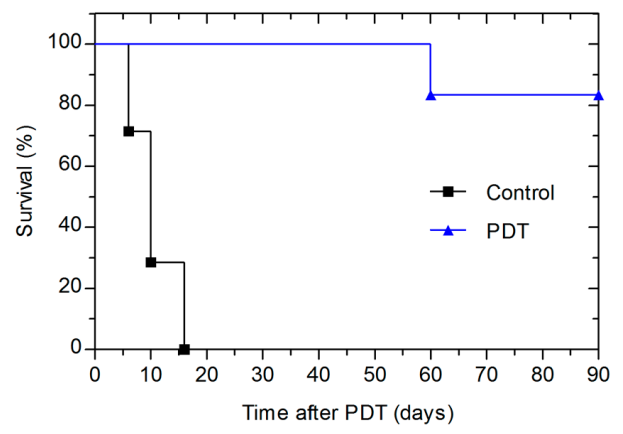

Figure 3. Kaplan Meier plot for BALB/c animals with CT26 untreated tumours and tumours treated with PDT with total light doses of $74 \mathrm{~J} / \mathrm{cm}^{2}(130 \mathrm{~mW})$ at $15 \mathrm{~min}$ after $1.5 \mathrm{mg} / \mathrm{kg}$ of redaporfin administration. 


\section{Discussion}

The redaporfin formulations administered intravenously to mice without illumination, even at the highest dose of $75 \mathrm{mg} / \mathrm{kg}$, seem to be very well tolerated by the animals. There were no observable signs of local irritation at the injection site, and no signs of photosensitivity appeared in any of the groups. These results are indicative of the safety of redaporfin and its formulation, confirming the very low toxicity in the absence of light observed during the in vitro screening stage, and suggest a comfortable safety margin in relation to the expected therapeutic dose. Indeed, the redaporfin-PDT protocol with DLI $=15 \mathrm{~min}, 1.5 \mathrm{mg} / \mathrm{kg}$ redaporfin and a light dose of $74 \mathrm{~J} / \mathrm{cm}^{2}$, proved to be effective and safe for male BALC/c mice. This means that the formulation used in the clinical studies, $\mathrm{CrEL} / \mathrm{EtOH} / \mathrm{NaCl} 0.9 \%(0.2: 1: 98.8, v: v: v)$, may deliver an effective drug dose at a CrEL level close to the CMC limit and well below the safe dose limit.

Safety toxicology in rats followed clinical blood-markers at different time-points after i.v. injection of redaporfin and after PDT to evaluate possible systemic toxicity. There were no visible signs of irritation at the injection site, and no light-avoidance behaviour. The blood markers confirmed that the redaporfin formulation, either at $1.5 \mathrm{mg} / \mathrm{kg}$ or at $15 \mathrm{mg} / \mathrm{kg}$, without the application of a PDT protocol is very well tolerated and does not cause significant alterations on the baseline levels of the evaluated parameters. The scenario was different when a vascular-PDT protocol was applied in healthy rats. This protocol used $1.5 \mathrm{mg} / \mathrm{kg}$ of redaporfin, a DLI of $15 \mathrm{~min}$ and a light fluence of $74 \mathrm{~J} / \mathrm{cm}^{2}$, which was shown to be very efficient in the PDT treatment of BALB/c male mice ( $83 \%$ cures). In healthy rats, it led to a strong local inflammatory response in and around the illuminated area, and to the formation of a necrotic scab covering perfectly the illuminated tissue. In addition to these macroscopic observations, some of the clinical markers for the hepatic function and muscle integrity showed a large increase $24 \mathrm{~h}$ after PDT, which are assigned to the considerable destruction of skeletal muscle caused by redaporfin-PDT in this model. On the day after PDT, there was also a significant but transient increase of the population of neutrophils in circulation, which could be a result of their recruitment in response to the local inflammatory reaction to infiltrate the affected tissues. Nevertheless, these acute changes were temporary, as demonstrated by their attenuation $72 \mathrm{~h}$ after the illumination and after one week returned to their levels before PDT. The reactions to the i.v. administration of redaporfin are completely reversible and far less significant than those reported in the scientific discussion document of the EMA for Foscan ${ }^{\circledR}$, which was approved as systemic photosensitizer for head and neck cancer. The i.v. administration of Foscan ${ }^{\circledR}$ to mice and rats exposed only normal light conditions, without illumination, led to phototoxicity reactions on exposed areas of the skin and to systemic toxicity characterized by significant changes in haematological and haematopoietic parameters and increased spleen and liver weights, even at doses as low as $0.85 \mathrm{mg} / \mathrm{kg}$ [26].

It is interesting to remark that the vascular-PDT protocol used in this study with male BALB/c mice $(1.5 \mathrm{mg} / \mathrm{kg}$ and $98 \mathrm{~J})$ did not lead to PDT-induced lethality, whereas a similar protocol with female BALB/c mice $(1.5 \mathrm{mg} / \mathrm{kg}$ and $78 \mathrm{~J})$ led to the death of five out of six the animals in less than three days after PDT $[9,10]$. We assign this difference to the smaller size of the female BALB/c mice, which had between $16.9 \mathrm{~g}$ and $19.4 \mathrm{~g}$ at the time of that treatment, with respect to the male BALB/c mice in this study, which weighed approximately $30 \mathrm{~g}$. PDT-induced lethality decreases dramatically with body weight for the same drug and light dose when the light dose is expressed in Joules, or in $\mathrm{J} / \mathrm{cm}^{2}$ and the illuminated area is kept constant. The tissue damage produced by the ROS does not scale with the body weight for a constant light dose. For example, a $20 \mathrm{~g}$ mouse has a surface area of $66 \mathrm{~cm}^{2}$ and we illuminated $1.33 \mathrm{~cm}^{2}$ [27]. A $60 \mathrm{~kg}$ adult has a surface area of $1.6 \mathrm{~m}^{2}$ and the equivalent PDT-induced lethality dose must take in account both the weight of the patient to establish the drug dose and the surface area illuminated to establish the light dose. 


\section{Materials and Methods}

\subsection{Chemicals}

The redaporfin was supplied by Luzitin, SA in sealed vials with weighed amounts under nitrogen atmosphere, and was stored at approximately $-18^{\circ} \mathrm{C}$, in the dark. All procedures involving the handling of redaporfin, either as a solid or in solution, were performed in conditions of reduced luminosity (in the absence of direct light). Cremophor ${ }^{\circledR}$ EL was purchased from Sigma-Aldrich (St. Louis, MO, USA). Absolute ethanol and $\mathrm{NaCl}$ were obtained from Merck (Darmstadt, Germany).

\subsection{Animals}

The use of laboratory animals in this study was authorized by the Portuguese Veterinary Authority -authorization number 0420/000/000/2011. BALB/c female mice with 8 weeks of age and female Wistar Han rats with 10 weeks of age were supplied by Charles River Laboratories (Barcelona, Spain). They were maintained with free access to food and water in a room with controlled cycle of $12 \mathrm{~h}$ light/dark. At the end of the study, animals were anaesthetised with a mixture of ketamine $100 \mathrm{mg} / \mathrm{kg}$ (Clorketam 1000, Vetoquinol, Barcarena, Portugal) and xylazine $10 \mathrm{mg} / \mathrm{kg}$ (Rompun 2\%, Bayer, Carnaxide, Portugal) and sacrificed by cervical dislocation.

\subsection{Dose Escalation Study}

\subsubsection{Redaporfin Formulations}

Each test dose of redaporfin $(15,21,26.3,30,37.5$ and $75 \mathrm{mg} / \mathrm{kg})$ was prepared as an individual formulation for i.v. administration. The formulation containing $\mathrm{CrEL} / \mathrm{EtOH} / \mathrm{NaCl} 0.9 \%$ was the same for all doses and was a modified version of the formulation developed and optimized for redaporfin-PDT of BALB/c [9,10], and DBA/2 mice [25] with subcutaneously implanted colon CT26 and melanoma S91 tumours, respectively. The proportions of $\mathrm{CrEL}$ and EtOH relative to redaporfin had to be significantly increased in this study to allow for the complete solubilisation of the necessary amount of redaporfin to reach the defined maximum dose of $75 \mathrm{mg} / \mathrm{kg}$. However, $\mathrm{CrEL}$ and EtOH were kept within the recommended limits for i.v. administration in mice [28,29]. The modified formulation $\mathrm{CrEL} / \mathrm{EtOH} / \mathrm{NaCl}$ 0.9\% (5:10:85, v:v:v) was prepared weighing the desired amount of redaporfin was into a $2 \mathrm{ml}$ microtube and dissolving it with the appropriated volumes of CrEL and absolute ethanol through alternated cycles of $30 \mathrm{~s}$ of vortex mixing followed by $5 \mathrm{~min}$ in an ultra-sound bath. Then, the solution was transferred to another tube containing the appropriated volume of $\mathrm{NaCl} 0.9 \%$ and was homogenised through vortex mixing, resulting in a limpid dark green solution. The complete solubilisation of redaporfin was confirmed by the absence of precipitate after a $5 \mathrm{~min}$ centrifugation at $4000 \mathrm{rpm}$. As expected, the difficulties in the solubilisation of redaporfin in the $\mathrm{CrEL} / \mathrm{EtOH}$ mixture increased dramatically with the concentration of the molecule. Consequently, the formulation for $75 \mathrm{mg} / \mathrm{kg}$ of redaporfin $(7.5 \mathrm{mg} / \mathrm{mL})$ was the maximum feasible dose.

\subsubsection{Intravenous Administration}

The final formulations listed in Table 2 were slowly injected in the mice tail vein using a syringe with a $26 \mathrm{G}$ needle in a proportion of $200 \mu \mathrm{L}$ per $20 \mathrm{~g}$ of mouse body weight. The first 6 groups (G0 to G5) were administered and followed in the first stage of the study. After the end of this first stage, group G6 was then administered and followed. 
Table 2. Summary of the study groups and the correspondent administered redaporfin i.v. formulations.

\begin{tabular}{cccc}
\hline Test Group & N & Redaporfin $\mathbf{( m g} / \mathbf{k g})$ & Redaporfin $(\mathbf{m g} / \mathbf{m L})$ \\
\hline G0 (Control) & 5 & 0.0 & 0.00 \\
G1 & 5 & 15.0 & 1.50 \\
G2 & 5 & 21.0 & 2.10 \\
G3 & 5 & 26.3 & 2.63 \\
G4 & 5 & 30.0 & 3.00 \\
G5 & 5 & 37.5 & 3.75 \\
G6 & 4 & 75.0 & 7.50 \\
\hline
\end{tabular}

\subsubsection{Mice Follow-up}

After administration, mice were evaluated at least once a week during 5 weeks. The following observations were registered: body weight, local reactions at the site of injection, light sensitivity/avoidance and general condition.

\subsection{Safety Toxicology Study}

\subsubsection{Redaporfin Formulation}

A redaporfin formulation in $\mathrm{CrEL} / \mathrm{EtOH} / \mathrm{NaCl} 0.9 \%$ was prepared first dissolving the defined amount of PS in the appropriated volumes of CrEL and absolute ethanol, using alternated cycles of $30 \mathrm{~s}$ of vortex mixing followed by $5 \mathrm{~min}$ in an ultra-sound bath. Next, the solution was transferred to a tube containing the appropriated volume of $\mathrm{NaCl} 0.9 \%$, and was carefully homogenised, resulting in a limpid dark green solution. The complete solubilisation of redaporfin was confirmed by the absence of precipitate after a $5 \mathrm{~min}$ centrifugation at $4000 \mathrm{rpm}$. The final formulation for the i.v. administration of $1.5 \mathrm{mg} / \mathrm{kg}$ of redaporfin in Wistar rats was composed of CrEL/EtOH/NaCl 0.9\% (1.2:5.7:93.1, v:v:v) and had a redaporfin concentration of $0.86 \mathrm{mg} / \mathrm{mL}$. The formulation used to deliver $15 \mathrm{mg} / \mathrm{kg}$ of redaporfin required $\mathrm{CrEL} / \mathrm{EtOH} / \mathrm{NaCl}$ 0.9\% (6.1:28.8:65.1, v:v:v) to allow the solubilisation of the higher amount of PS, and had a final concentration of $8.63 \mathrm{mg} / \mathrm{mL}$ of redaporfin.

\subsubsection{Intravenous Injection, PDT and Blood Collection}

Seven groups of animals were randomly organized $(n=4): 4$ non-illuminated groups and 3 groups that received a light dose after the administration of redaporfin. The non-illuminated were: non-treated control, redaporfin $1.5 \mathrm{mg} / \mathrm{kg}$, redaporfin $15 \mathrm{mg} / \mathrm{kg}$, and vehicle (the same vehicle used in the $15 \mathrm{mg} / \mathrm{kg}$ formulation, which contained the higher amounts of $\mathrm{CrEL}$ and EtOH). The 3 groups that received laser illumination $\left(74 \mathrm{~J} / \mathrm{cm}^{2}\right.$, diameter of illumination $\left.\varnothing=10 \mathrm{~mm}\right)$ were illuminated $15 \mathrm{~min}$ after the i.v. administration of redaporfin $1.5 \mathrm{mg} / \mathrm{kg}$ followed by. Rats from these 3 groups were illuminated in the muscle of the right thigh, previously shaved, using a diode laser type LA0873, S/N M070301 (Hamamatsu, Shizuoka, Japan) controlled with a ThorLabs 500 mA ACC/APC Laser Diode Controller (Munich, Germany) and in-house electronics, emitting $130 \mathrm{~mW}$ at $749 \mathrm{~nm}$, which was hand-held during the illumination. The time-points for the terminal blood collection were $24 \mathrm{~h}$, $72 \mathrm{~h}$, and 1 week after PDT for the irradiated groups, and $24 \mathrm{~h}$ after the administration for the other groups. Due to the volume of blood needed for the haematological and biochemistry tests, the procedure for blood collection was terminal. For the administration, illumination and blood collection rats were anesthetised with an intraperitoneal injection of a mixture of ketamine $75 \mathrm{mg} / \mathrm{kg}$ and xylazine $10 \mathrm{mg} / \mathrm{kg}$. At the defined time-points, $2-2.5 \mathrm{~mL}$ of blood were drawn from the abdominal aorta and, immediately after, the animals were sacrificed by cervical dislocation. 


\subsubsection{Blood Analysis}

Blood tests (haematology and serum biochemistry) were outsourced to a Clinical Analysis Laboratory and were performed using standard clinical procedures and equipment.

Immediately after collection, each blood sample was fractioned: $1 \mathrm{~mL}$ was transferred to an haematology tube containing ethylenediamine tetraacetic acid (EDTA) and gently homogenised, and the remaining, for serum biochemistry, was dispensed into a $2 \mathrm{~mL}$ microtube and was allowed to cloth at ambient temperature during $30 \mathrm{~min}$. Serum was separated by centrifugation at $4000 \mathrm{rpm}$ for $10 \mathrm{~min}$, and $0.5 \mathrm{~mL}$ of supernatant were transferred to a new tube.

Blood for haematology and serum were stored at $2-8{ }^{\circ} \mathrm{C}$ and analysed in the same day of collection. For manual leukocyte differential counts, a blood smear was prepared for each blood sample after blood collection, using a drop of EDTA-anticoagulated blood from the haematology tube. When dry, the smear was fixed with methanol for $3 \mathrm{~min}$, and then left to dry in vertical position. Slides were stored at ambient temperature until processing and analysis.

The haematology test evaluated the following parameters: Red Blood Cells $\left(\times 10^{12} / \mathrm{L}\right)$. Reticulocytes (\%). Haemoglobin (g/dL). Haematocrit (\%). Mean Corpuscular Volume (fL). Mean Corpuscular Haemoglobin (pg). Mean Corpuscular Haemoglobin Concentration (g/L). Red Cell Distribution Width $(\%)$. Platelets $\left(\times 10^{9} / \mathrm{L}\right)$. Mean Platelet Volume (fL). Plateletcrit $(\%)$. Platelet Distribution Width (\%). White Blood Cells $\left(\times 10^{9} / \mathrm{L}\right)$. White Blood Cells Differential Count.

The serum biochemistry test evaluated the following parameters: Glucose (mg/dL). Urea (mg/dL). Total Protein (g/L). Cholesterol (mg/dL). Triglycerides (mg/mL). Aspartate Aminotransferase (IU/L). Alanine Aminotransferase (IU/L). $\gamma$-Glutamyl Transpeptidase (IU/L). Alkaline Phosphatase (IU/L). Ureic Nitrogen (mg/dL). Creatine Kinase (IU/L). Lactate Dehydrogenase (IU/L). Creatinine (mg/dL). Bilirubin (mg/dL).

Results are presented for each group and time-point as average \pm SD. Differences between test and control groups were evaluated by one-way analysis of variance (ANOVA), using GraphPad Prism software (V5.01), with Tukey's post hoc test for multiple pair-wise comparisons. Differences were considered statistically significant for $p<0.05$.

\subsection{PDT Treatment}

Male BALB/c mice, approximately 3 months old ( $c a .25 \mathrm{~g}$ ), were implanted with 500,000 CT26 cells in the left thigh, and the tumours were allowed to grow to a volume of $30-50 \mathrm{~mm}^{3}$. Redaporfin formulation were prepared by dissolving the desired amount of redaporfin in a given volume of CrEL (Sigma, Steinheim, Germany) mixed in 1:1 (v:v) proportion with ethanol 99.8\% (Sigma) followed by dilution by a factor of 50 in $\mathrm{NaCl} 0.9 \%$ aqueous solution. When the tumours reached the size for the treatment, an appropriate volume of a freshly prepared redaporfin formulation was i.v. injected to administer at a dose of $1.5 \mathrm{mg} / \mathrm{kg}$ body weight. Illumination of the tumour area was performed with an Omicron laser model LDM750.300.CWA.L.M (Rodgau-Dudenhofen, Germany), emitting at $749 \mathrm{~nm}$, connected to a glass optical fibre model FD (Medlight, Ecublens, Switzerland) coupled with a microlens, which was held in a fixed position and directed to the tumour. The protocol parameters varied in this study were: (i) DLI $=15 \mathrm{~min}$; (ii) redaporfin dose $=1.5 \mathrm{mg} / \mathrm{kg}$; (iii) light dose $=74 \mathrm{~J} / \mathrm{cm}^{2}$; (iv) laser output power $=130 \mathrm{~mW}$; (v) $\varnothing=13 \mathrm{~mm}$.

\section{Conclusions}

The exploratory dose escalation and toxicology studies presented in this work demonstrate the low toxicity of redaporfin and its formulation, even when combined with a biologically effective PDT protocol. The only trace of toxicity was the observation of elevated transaminases after illumination of healthy tissue. These studies were confirmed and complemented with pharmacology and toxicology studies in rat and dog, performed by a contract research organization (CRO) in accordance to all regulatory good laboratory practice (GLP) requisites, to complete the nonclinical package required 
for the clinical trial application for advanced cancer. Nevertheless, the demonstration that our redaporfin formulations are well-tolerated and non-toxic to rodents, does not totally remove the possibility of observing hypersensitivity reactions in humans, because rodents are much less sensitive to Cremophor EL than humans. The introduction in the clinic of formulations containing CrEL must always be accompanied by careful surveillance of hypersensitivity reactions. Remarkably, redaporfin-PDT of a BALB/c mouse model with a drug dose 50 times lower than the highest dose tested in the toxicity study, provided significant survival advantage, with a cure rate of $83 \%$. This is an encouraging result for one single PDT treatment of subcutaneously implanted CT26 colon carcinoma.

Acknowledgments: This work was sponsored by Luzitin, SA, which received additional financial support from the European Commission through the National Strategic Reference Framework's Programme (QREN), project no. 5356. Janusz M. Dabrowski thanks the National Science Centre, Poland (NCN) for grant 2013/11/D/ST5/02995.

Author Contributions: Luis B. Rocha, Luis G. Arnaut, Janusz M. Dąbrowski and Sérgio Simões conceived and designed the experiments; Luis B. Rocha., Fábio Schaberle and Janusz M. Dabrowski performed the experiments; Luis B. Rocha analysed the data; Luis B. Rocha and Luis G. Arnaut wrote the paper.

Conflicts of Interest: Bluepharma-Indústria Farmacêutica SA, sponsors the PhD studies of Luis B. Rocha. Luis G. Arnaut is the inventor of patents licenced to Luzitin, SA. The funding sponsors had no role in the design of the study; in the collection, analyses, or interpretation of data; in the writing of the manuscript, and in the decision to publish the results.

\section{Abbreviations}

The following abbreviations are used in this manuscript: $\gamma$-GT: Gamma-glutamyl transferase; ALP: alkaline phosphatase; ANOVA: analysis of variance; ALT: alanine aminotransferase; AST: aspartate aminotransferase; BA: basophils; BIL: total bilirubin; BUN: blood urea nitrogen; BW: body weight; CHOL: total cholesterol; CK: creatine kinase; CRE: creatinine; CrEL: Cremophor EL; CRO: Contract Research Organization; DLI: drug-light interval; EDTA: ethylenediamine tetraacetic acid; EMA: European Medicines Agency; EO: eosinophils; EtOH: ethanol; GLP: Good Laboratory Practice; GLU: glucose; Hb: haemoglobin; HCT: haematocrit; ICH: International Council for Harmonisation of Technical Requirements for Pharmaceuticals for Human Use; i.v.: intravenous; LDH: lactate dehydrogenase; LY: lymphocytes; MCH: mean corpuscular haemoglobin; MCHC: mean corpuscular haemoglobin concentration; MCV: mean corpuscular volume; min: minutes; MO: monocytes; MPV: mean platelet volume; MTD: maximum tolerated dose; NE: neutrophils; PCT: plateletcrit; PDT: Photodynamic Therapy; PDW: platelet distribution width; PLT: platelets; PS: photosensitizer; RBC: red blood cells; RDW: red blood cell distribution width; Retic: reticulocytes; ROS: reactive oxygen species; SD: standard deviation; TG: triglycerides; TP: total protein; WBC: white blood cells. 


\section{Appendix A}

Table A1. Results of the haematology tests from all study groups, presented as average \pm SD.

\begin{tabular}{|c|c|c|c|c|c|c|c|}
\hline Haematology & Control & Vehicle & $1.5 \mathrm{mg} / \mathrm{kg}$ & $15 \mathrm{mg} / \mathrm{kg}$ & $\begin{array}{c}1.5 \mathrm{mg} / \mathrm{kg} \\
\text { PDT }+24 \mathrm{~h}\end{array}$ & $\begin{array}{c}1.5 \mathrm{mg} / \mathrm{kg} \\
\text { PDT }+72 \mathrm{~h}\end{array}$ & $\begin{array}{c}1.5 \mathrm{mg} / \mathrm{kg} \\
\text { PDT + } 1 \text { week }\end{array}$ \\
\hline $\operatorname{RBC}\left(\times 10^{12} / \mathrm{L}\right)$ & $6.5 \pm 0.3$ & $6.5 \pm 0.3$ & $7.2 \pm 0.3$ & $6.4 \pm 0.2$ & $6.7 \pm 0.3$ & $6.1 \pm 0.2$ & $6.2 \pm 0.4$ \\
\hline Retic (\%) & $1.3 \pm 0.1$ & $1.4 \pm 0.1$ & $1.3 \pm 0.1$ & $1.4 \pm 0.1$ & $1.2 \pm 0.1$ & $1.3 \pm 0.1$ & NP \\
\hline $\mathrm{Hg}(\mathrm{g} / \mathrm{L})$ & $13.4 \pm 0.5$ & $13.5 \pm 0.2$ & $14.1 \pm 0.2$ & $13.1 \pm 0.2$ & $13.8 \pm 0.1$ & $12.0 \pm 0.2$ & $12.6 \pm 0.7$ \\
\hline НCT (\%) & $36.3 \pm 2.0$ & $36.3 \pm 0.6$ & $39.7 \pm 1.0$ & $35.1 \pm 0.6$ & $39.5 \pm 0.7$ & $34.6 \pm 1.1$ & $35.5 \pm 1.8$ \\
\hline $\operatorname{MCV}(\mathrm{fL})$ & $56.1 \pm 1.7$ & $55.1 \pm 1.8$ & $55.2 \pm 1.3$ & $55.0 \pm 1.3$ & $59.5 \pm 2.0$ & $56.9 \pm 1.8$ & $57.1 \pm 1.0$ \\
\hline $\mathrm{MCH}(\mathrm{pg})$ & $20.8 \pm 0.8$ & $20.6 \pm 1.1$ & $19.6 \pm 0.9$ & $20.6 \pm 0.7$ & $20.7 \pm 1.0$ & $19.8 \pm 0.5$ & $20.2 \pm 0.3$ \\
\hline $\mathrm{MCHC}(\mathrm{g} / \mathrm{L})$ & $37.1 \pm 0.8$ & $37.3 \pm 0.8$ & $35.5 \pm 0.8$ & $37.4 \pm 0.5$ & $34.9 \pm 0.5$ & $34.8 \pm 0.6$ & $35.4 \pm 0.6$ \\
\hline RDW (\%) & $12.0 \pm 0.4$ & $12.3 \pm 1.1$ & $12.3 \pm 1.3$ & $12.7 \pm 1.0$ & $11.2 \pm 0.6$ & $11.9 \pm 0.9$ & $13.0 \pm 1.3$ \\
\hline $\operatorname{PLT}\left(\times 10^{9} / \mathrm{L}\right)$ & $740 \pm 62$ & $629 \pm 90$ & $801 \pm 56$ & $654 \pm 83$ & $615 \pm 167$ & $610 \pm 34$ & $\mathrm{NM}$ \\
\hline MPV (fL) & $5.8 \pm 0.2$ & $5.6 \pm 0.3$ & $5.4 \pm 0.1$ & $5.7 \pm 0.2$ & $6.1 \pm 0.4$ & $5.7 \pm 0.2$ & $5.7 \pm 0.2$ \\
\hline РCТ $(\%)$ & $42.7 \pm 2.4$ & $35.0 \pm 3.4$ & $43.4 \pm 2.4$ & $37.4 \pm 6.1$ & $37.4 \pm 8.6$ & $35.0 \pm 1.0$ & $67.3 \pm 9.4$ \\
\hline PDW (\%) & $17.0 \pm 0.2$ & $16.7 \pm 0.6$ & $16.9 \pm 0.8$ & $16.8 \pm 0.5$ & $17.2 \pm 0.4$ & $16.7 \pm 0.3$ & $16.6 \pm 0.3$ \\
\hline $\operatorname{WBC}\left(\times 10^{9} / \mathrm{L}\right)$ & $5.1 \pm 0.6$ & $3.5 \pm 0.7$ & $7.0 \pm 2.0$ & $3.6 \pm 0.4$ & $6.9 \pm 1.7$ & $5.4 \pm 0.8$ & $4.8 \pm 0.5$ \\
\hline NE $(\%)$ & $16.0 \pm 6.4$ & $14.0 \pm 3.5$ & $11.0 \pm 5.0$ & $20.7 \pm 9.3$ & $53.3 \pm 10.2$ & $28.3 \pm 7.8$ & NP \\
\hline $\mathrm{NE}\left(\times 10^{9} / \mathrm{L}\right)$ & $0.8 \pm 0.2$ & $0.5 \pm 0.1$ & $0.8 \pm 0.5$ & $0.8 \pm 0.4$ & $3.7 \pm 1.0$ & $1.5 \pm 0.4$ & $\mathrm{NP}$ \\
\hline LY $(\%)$ & $82.0 \pm 6.3$ & $84.3 \pm 3.4$ & $85.3 \pm 5.0$ & $76.0 \pm 9.5$ & $41.3 \pm 10.0$ & $66.0 \pm 7.5$ & NP \\
\hline $\mathrm{LY}\left(\times 10^{9} / \mathrm{L}\right)$ & $4.2 \pm 0.7$ & $3.0 \pm 0.6$ & $5.9 \pm 1.6$ & $2.7 \pm 0.2$ & $2.9 \pm 1.2$ & $3.6 \pm 0.7$ & $\mathrm{NP}$ \\
\hline $\mathrm{MO}(\%)$ & $1.8 \pm 1.5$ & $1.8 \pm 2.1$ & $3.0 \pm 0.8$ & $3.3 \pm 1.5$ & $5.3 \pm 0.6$ & $5.0 \pm 2.2$ & NP \\
\hline $\mathrm{MO}\left(\times 10^{9} / \mathrm{L}\right)$ & $0.1 \pm 0.1$ & $0.1 \pm 0.1$ & $0.2 \pm 0.1$ & $0.1 \pm 0.1$ & $0.4 \pm 0.1$ & $0.3 \pm 0.1$ & NP \\
\hline EO $(\%)$ & $0.3 \pm 0.5$ & $0.0 \pm 0.0$ & $0.8 \pm 1.0$ & $0.0 \pm 0.0$ & $0.0 \pm 0.0$ & $0.8 \pm 1.0$ & NP \\
\hline $\mathrm{EO}\left(\times 10^{9} / \mathrm{L}\right)$ & $0.0 \pm 0.0$ & $0.0 \pm 0.0$ & $0.1 \pm 0.1$ & $0.0 \pm 0.0$ & $0.0 \pm 0.0$ & $0.0 \pm 0.1$ & $\mathrm{NP}$ \\
\hline BA $(\%)$ & $0.0 \pm 0.0$ & $0.0 \pm 0.0$ & $0.0 \pm 0.0$ & $0.0 \pm 0.0$ & $0.0 \pm 0.0$ & $0.0 \pm 0.0$ & NP \\
\hline $\mathrm{BA}\left(\times 10^{9} / \mathrm{L}\right)$ & $0.0 \pm 0.0$ & $0.0 \pm 0.0$ & $0.0 \pm 0.0$ & $0.0 \pm 0.0$ & $0.0 \pm 0.0$ & $0.0 \pm 0.0$ & NP \\
\hline
\end{tabular}

Table A2. Results of the serum biochemistry tests from all study groups, presented as average \pm SD.

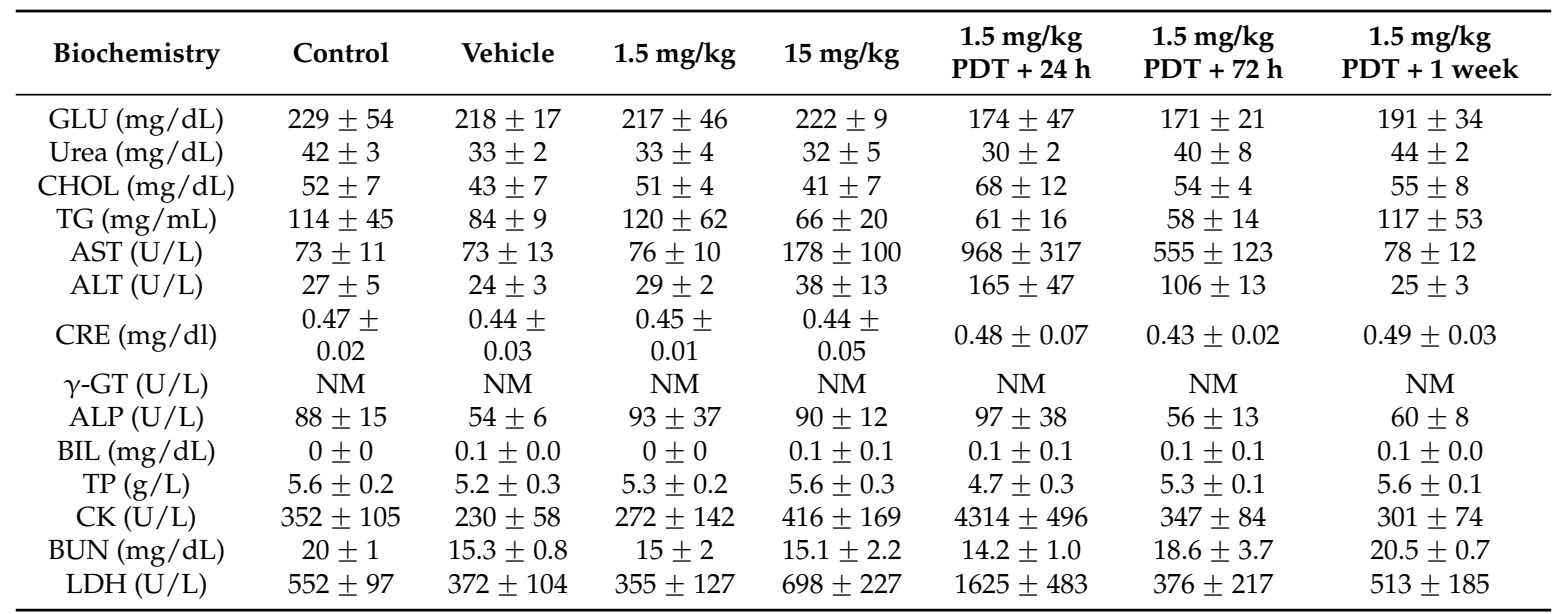

NM = Not measurable - out of range; $\gamma$-GT: Gamma-glutamyl transferase; ALP: alkaline phosphatase; ALT: alanine aminotransferase; AST: aspartate aminotransferase; BIL: total bilirubin; BUN: blood urea nitrogen; CHOL: total cholesterol; CK: creatine kinase; CRE: creatinine; GLU: glucose; LDH: lactate dehydrogenase; TG: triglycerides; TP: total protein. 


\section{References}

1. Agostinis, P.; Berg, K.; Cengel, K.A.; Foster, T.H.; Girotti, A.W.; Gollnick, S.O.; Hahn, S.M.; Hamblin, M.R.; Juzeniene, A.; Kessel, D.; et al. Photodynamic therapy of cancer: an update. CA Cancer J. Clin. 2011, 61, 250-281. [CrossRef] [PubMed]

2. Dabrowski, J.M.; Arnaut, L.G. Photodynamic therapy (PDT) of cancer: From local to systemic treatment. Photochem. Photobiol. Sci. 2015, 14, 1765-1780. [CrossRef] [PubMed]

3. Castano, A.P.; Demidova, T.N.; Hamblin, M.R. Mechanisms in photodynamic therapy: Part three-Photosensitizer pharmacokinetics, biodistribution, tumor localization and modes of tumor destruction. Photodiag. Photodyn. Ther. 2005, 2, 91-106. [CrossRef]

4. Castano, A.P.; Mroz, P.; Hamblin, M.R. Photodynamic therapy and anti-tumour immunity. Nat. Rev. Cancer 2006, 6, 535-545. [CrossRef] [PubMed]

5. ICH, Guideline S9-Nonclinical Evaluation for Anticancer Pharmaceuticals. Available online: http://122.3.253.116/attachments/article/99526/S9\%20Step\%204.pdf. URL (accessed on 29 October 2015).

6. Chevalier, S.; Cury, F.L.; Scarlata, E.; El-Zayat, E.; Hamel, L.; Rocha, J.; Zouanat, F.Z.; Moussa, S.; Scherz, A.; Elhilali, M.; et al. Endoscopic Vascular Targeted Photodynamic Therapy with the Photosensitizer WST11 for Benign Prostatic Hyperplasia in the Preclinical Dog Model. J. Urol. 2013, 190, 1946-1953. [CrossRef] [PubMed]

7. Lin, N.; Li, C.; Wang, Z.; Zhang, J.; Ye, X.; Gao, W.; Wang, A.; Jin, H.; Wei, J. A safety study of a novel photosensitizer, sinoporphyrin sodium, for photodynamic therapy in Beagle dogs. Photochem. Photobiol. Sci. 2015, 14, 815-832. [CrossRef] [PubMed]

8. Arnaut, L.G.; Pereira, M.M.; Dabrowski, J.M.; Silva, E.F.; Schaberle, F.A.; Abreu, A.R.; Rocha, L.B.; Barsan, M.M.; Urbanska, K.; Stochel, G.; et al. Photodynamic therapy efficacy enhanced by dynamics: The role of charge transfer and photostability in the selection of photosensitizers. Chemistry 2014, 20, 5346-5357. [CrossRef] [PubMed]

9. Saavedra, R.; Rocha, L.B.; Dabrowski, J.M.; Arnaut, L.G. Modulation of biodistribution, pharmacokinetics, and photosensitivity with the delivery vehicle of a bacteriochlorin photosensitizer for photodynamic therapy. ChemMedChem 2014, 9, 390-398. [CrossRef] [PubMed]

10. Rocha, L.B.; Gomes-da-Silva, L.C.; Dabrowski, J.M.; Arnaut, L.G. Elimination of primary tumours and control of metastasis with rationally designed bacteriochlorin photodynamic therapy regimens. Eur. J. Cancer 2015, 51, 1822-1830. [CrossRef] [PubMed]

11. Ten Tije, A.J.; Verweij, J.; Loos, W.J.; Sparreboom, A. Pharmacological effects of formulation vehicles: Implications for cancer chemotherapy. Clin. Pharmacokinet. 2003, 42, 665-685. [CrossRef] [PubMed]

12. Woodburn, K.; Chang, C.K.; Lee, S.; Henderson, B.; Kessel, D. Biodistribution and PDT efficacy of a ketochlorin photosensitizer as a function of the delivery vehicle. Photochem. Photobiol. 1994, 60, 154-159. [CrossRef] [PubMed]

13. Szebeni, J.; Muggia, F.M.; Alving, C.R. Complement activation by Cremophor EL as a possible contributor to hypersensitivity to paclitaxel: an in vitro study. J. Natl. Cancer Inst. 1998, 90, 300-306. [CrossRef] [PubMed]

14. Gelderblom, H.; Verweij, J.; Nooter, K.; Sparreboom, A. Cremophor EL: The drawbacks and advantages of vehicle selection for drug formulation. Eur. J. Cancer 2001, 37, 1590-1598. [CrossRef]

15. Boehm, D.K.; Maksymiuk, A.W. Paclitaxel premedication regimens. J. Natl. Cancer Inst. 1996, 88, 463-465. [CrossRef] [PubMed]

16. Commission, E. Community register of orphan medicinal products. Available online: http://ec.europa.eu/ health/documents/community-register/html/o1470.htm (accessed on 11 November 2015).

17. Photodynamic Therapy With LUZ11 in Advanced Head and Neck Cancer. Available online: https:/ / clinicaltrials.gov/ct2/show /NCT02070432?term=photodynamic+therapy\&recr=Open\&rank=37 (accessed on 9 October 2015).

18. Zhang, Z.; Jin, H.; Bao, J.; Fang, F.; Wei, J.; Wang, A. Intravenous repeated-dose toxicity study of ZnPcS2P2-based-photodynamic therapy in Wistar rats. Photochem. Photobiol. Sci. 2006, 5, 1006-1017. [CrossRef] [PubMed] 
19. Cho, Y.M.; Onodera, H.; Ueda, M.; Imai, T.; Hirose, M. A 13-week subchronic toxicity study of dietary administered morin in F344 rats. Food Chem. Toxicol. 2006, 44, 891-897. [CrossRef] [PubMed]

20. Green, T.; Dow, J.; Foster, J. Increased formic acid excretion and the development of kidney toxicity in rats following chronic dosing with trichloroethanol, a major metabolite of trichloroethylene. Toxicology 2003, 191, 109-119. [CrossRef]

21. Charles River Laboratories. Baseline hematology and clinical chemistry values for charles river wistar rats. Available online: http://www.criver.com/files/pdfs/rms/wistar-rats/rm_rm_r_hematology_crl_wi_br_ sex_age.aspx (accessed on 9 October 2015).

22. Brancaccio, P.; Lippi, G.; Maffulli, N. Biochemical markers of muscular damage. Clin. Chem. Lab. Med. 2010, 48, 757-767. [CrossRef] [PubMed]

23. Mroz, P.; Castano, A.P.; Hamblin, M.R. Stimulation of dendritic cells enhances immune response after photodynamic therapy. Biophotonics Immune Responses 2009, 7178, 717803.

24. Mroz, P.; Yaroslavsky, A.; Kharkwal, G.B.; Hamblin, M.R. Cell death pathways in photodynamic therapy of Cancer. Cancers 2011, 3, 2516-2539. [CrossRef] [PubMed]

25. Krzykawska-Serda, M.; Dabrowski, J.M.; Arnaut, L.G.; Szczygiel, M.; Urbanska, K.; Stochel, G.; Elas, M. The role of strong hypoxia in tumors after treatment in the outcome of bacteriochlorin-based photodynamic therapy. Free Radic. Biol. Med. 2014, 73, 239-251. [CrossRef] [PubMed]

26. European Medicines Agency (EMA). European public assessment report (EPAR) for Foscan-Scientific Discussion. Available online: http://www.ema.europa.eu/docs/en_GB/document_library/ EPAR_-_Scientific_Discussion/human/000318/WC500024394.pdf (accessed on 22 October 2015).

27. Freireich, E.J.; Gehan, E.A.; Rall, D.P.; Schmidt, L.H.; Skipper, H.E. Quantitative comparison of toxicity of anticancer agents in mouse, rat, hamster, dog, monkey, and man. Cancer Chemother. Rep. 1966, 50, 219-244. [PubMed]

28. Schreckenberger, M.; Amberg, R.; Scheurich, A.; Lochmann, M.; Tichy, W.; Klega, A.; Siessmeier, T.; Grunder, G.; Buchholz, H.-G.; Landvogt, C.; et al. Acute alcohol effects on neuronal and attentional processing: Striatal reward system and inhibitory sensory interactions under acute ethanol challenge. Neuropsychopharmacology 2004, 29, 1527-1537. [CrossRef] [PubMed]

29. Li, P.; Zhao, L. Developing early formulations: Practice and perspective. Int. J. Pharm. 2007, 341, 1-19. [CrossRef] [PubMed]

(C) 2015 by the authors; licensee MDPI, Basel, Switzerland. This article is an open access article distributed under the terms and conditions of the Creative Commons by Attribution (CC-BY) license (http://creativecommons.org/licenses/by/4.0/). 